Journal of Teaching and Learning with Technology, Vol. 4, No. 2, December 2015, pp. 58-61.

doi: 10.14434/jotlt.v4n2.13720

Book Review

\title{
Minds Online: Teaching Effectively with Technology
}

\section{Britt Watwood $^{1}$}

Citation: Miller, M. (2014) Minds online: Teaching effectively with technology. Cambridge MA: Harvard University Press.

Publisher's Description: From wired campuses to smart classrooms to massive open online courses (MOOCs), digital technology is now firmly embedded in higher education. But the dizzying pace of innovation, combined with a dearth of evidence on the effectiveness of new tools and programs, challenges educators to articulate how technology can best fit into the learning experience. Minds Online is a concise, nontechnical guide for academic leaders and instructors who seek to advance learning in this changing environment, through a sound scientific understanding of how the human brain assimilates knowledge. Drawing on the latest findings from neuroscience and cognitive psychology, Miller Miller explores how attention, memory, and higher thought processes such as critical thinking and analytical reasoning can be enhanced through technology-aided approaches. She presents innovative ideas for how to use multimedia effectively, how to take advantage of learners' existing knowledge, and how to motivate students to do their best work and complete the course.

Michelle D. Miller's new book provides a readable review of research-based cognitive principles for improving learning through technology, focusing on attention, memory and thinking. The goal of this book is to guide practitioners with practical advise in order to develop a "cognitively optimized, fully online course." Miller is clear that technology alone does not promote learning. Learning requires focused attention, effortful practice, and motivation - concepts that align with recent syntheses of learning science such as Susan Ambrose's (2010) How Learning Works.

The first chapter asks two rhetorical questions. Is online learning here to stay? Does learning online work? Miller noted that just by asking these questions, we are holding technologically aided teaching to a higher standard than classroom teaching! She charts out principles for optimal college teaching excerpted from four "best practice" frameworks. These best practices do suggest that, with the conscious use of active learning processes, online learning does indeed work.

The book tackles some of the prevailing myths about the psychology of computing:

${ }^{1}$ Associate Director, Center for Advancing Teaching and Learning Through Research, Northeastern University, b.watwood@neu.edu 
- Use of the web "rewires" the brain

- Students today are "digital natives"

- Social networking destroys real-life social relationships

While there are grains of truth, she provides some interesting analysis of the realities behind these myths and what that might mean for teaching.

Her next three chapters explore attention, thinking and memory. It is easy to derail attention. Yet, attention can easily be shifted. As Miller noted:

"The inattentional blindness effect illustrates a broader truth about human perception and attention, that looking and seeing are two different things and that we are remarkably prone to missing stimuli when our attention is directed elsewhere."

While capacity cannot be expanded, it can be altered by practice. Actions that become automatic free up the brain to process other information. Attention is highly intertwined with visual processing, which is another facet of online course design that matters. The book explores change blindness, in which changes to the screen are not picked up readily. Most people think they perceive more change than they really do.

Working memory is an area of significant variation among individuals. Attention directs what goes in to working memory, so again, understanding attention is important to creating a learning environment. Miller suggested several strategies regarding attention and online learning.

- Ask students to respond - Chunk material into short segments and have students do something (answer a question, click on a hotspot, etc).

- Take advantage of automaticity - Use auto-grading features of LMS's to provide practice opportunities and feedback, with incentives for completion.

- Assess Cognitive Load - Positively impact cognitive load through design features. Poor instructions or requiring new features without practice can negatively increase cognitive load.

- Discourage Divided Attention - The web is full of distractions, but simply informing students that they should pay attention actually increases attention.

This focus on attention suggests that instructors should educate students about multitasking, make materials as seamless as possible, minimize extraneous attention drains, and keep them engaged through compelling activities.

From attention, the book then focuses on memory. Technology opens up new opportunities for learning that never existed in face-to-face classrooms. Technology allows one to build activities that capitalize on multiple interrelated sensory cues (video, audio, image, text, query, etc.), deeper-level processing, metacognition, and opportunities to engage the emotions.

Journal of Teaching and Learning with Technology, Vol. 4, No. 2, December 2015. jotlt.indiana.edu 
A key difference between experts and novices lies in how knowledge is organized. Experts see patterns and how concepts are linked, including how they are linked to prior knowledge. Miller explored research on testing effects and spacing effects. The book suggested five strategies for designing online learning experiences:

- Include frequent tests and test-like activities

- $\quad$ Structure for spaced study

- Involve emotions (carefully)

- Steer students into deeper learning

- Base new knowledge on old knowledge

Effective thinking is something that sets experts apart from novices. It is a skill that can be built with practice. Cognitive scientists have broken thinking down into the discrete areas of formal reasoning, decision-making, and problem solving. Formal reasoning is hard. Our brains tend to take shortcuts when faced with reasoning problems.

A fascinating section in this book dealt with the research on creativity. Students who are given explicit step-by-step instructions tend to produce less creative work products compared to those who were given less-structured directions. Miller noted that experts solve problems better - not because they are smarter but because they can draw on a richer base of stored and connected knowledge. She suggested that for online teachers, providing practice opportunities is important, but equally important is providing scaffolding in the form of knowledge organizations and conceptual interrelationships. This can help move students from the novice stage to a more expert-like stage of reasoning.

In designing online learning opportunities, one should integrate metacognitive activities with learning activities. This suggests that we as online teachers put some "thinking" into the questions we use as prompts in our courses.

The book effectively debunks the time honored learning styles of VAK (Visual, Auditory, and Kinesthetic), noting "VAK may go down as one of the greatest psychological myths of all time." The cognitive research suggests that we all have ALL styles and that there really is not one that dominates. She noted that people tend to not know what their "true" style is and have poor skills as self-assessing. Assuming one style can lead students to disengage if presented with an alternative style, negatively impact learning.

The take away for online teaching is that pictures, audio and video can enhance learning, but the multimedia needs to align with the learning, not overload or distract. Thinking inclusively, one should augment any multimedia with alternative options.

There are acknowledged motivational challenges between online and on campus teaching. "Motivation," as Miller noted, comes for the same Latin root as the word "to move" - mechanisms that put you in motion. The study of motivation is closely aligned with the study of emotion. The book explores the framework of self-determination theory, contrasting intrinsic and extrinsic motivations. This suggests that people are motivated by

Journal of Teaching and Learning with Technology, Vol. 4, No. 2, December 2015. jotltindiana.edu 
the need for three basic things - competence, relatedness, and autonomy. When students are cut off from any of these, motivation suffers.

Academic self-efficacy is a good predictor of academic success. Providing videos of "average" students who succeeded boosted self-efficacy, as did presenting grades in informational rather than controlling ways. Wording course materials in ways that suggest autonomy, such as "you might..." or "we suggest...", as well as tying course materials to student long-term goals, increase motivation.

An interesting section discussed motivation issues associated with a "fixed" mindset versus a "growth" mindset. If students have a fixed mindset, they carry a belief that intelligence is basically unchangeable, whereas those with a growth mindset believe that intelligence is not set in stone. Online instructors can sometimes unwittingly foster a mindset by the feedback they provide. Positive comments about intelligence, such as "you are smart" or "you are a math whiz!" actually feed a fixed mindset. Miller suggested that praise should be focused on the process: working hard, choosing good strategies, etc.

Motivation is a high stakes endeavor in online teaching, so Miller suggested that during the first week, we steer the focus towards the "why" of a course and away from the "what" - why study this topic, why this topic might change you as a student, why this topic is important to your future, rather than what is required, what you have to complete, or what the grading policies are. The "what's" are important and need to be covered, but they need to be covered after the "why's" have been covered, and better yet, after the students have engaged with the whys.

The book ends with tips to actively manage motivation in the course design. She provided a series of key questions to guide this process. Each question is linked with the cognitive principles behind the question as well as tools and techniques that address the question.

This is a very readable and useful book. There are many aspects that could be implemented immediately into one's online teaching. It connects some dots between effective teaching practices and the learning science behind why these practices work. I highly recommend adding his book to your personal library!

\section{References}

Ambrose, S.A.; Bridges, M.W.; DiPietro, M.; Lovett, M.C.; and Norman, M.K. (2010). How learning works: 7 research-based principles for smart teaching. San Francisco: Jossey-Bass.

Miller, M. (2014). Minds online: Teaching effectively with technology. Cambridge MA: Harvard University Press.

Journal of Teaching and Learning with Technology, Vol. 4, No. 2, December 2015. jotlt.indiana.edu 